Article

\title{
Large-Signal Linearity and High-Frequency Noise of Passivated AlGaN/GaN High-Electron Mobility Transistors
}

\author{
Yu-Shyan Lin * and Shin-Fu Lin
}

Citation: Lin, Y.-S.; Lin, S.-F. Large-Signal Linearity and HighFrequency Noise of Passivated AlGaN/GaN High-Electron Mobility Transistors. Micromachines 2021, 12, 7. https://dx.doi.org/10.3390/mi12 010007

Received: 19 November 2020 Accepted: 21 December 2020 Published: 24 December 2020

Publisher's Note: MDPI stays neutral with regard to jurisdictional claims in published maps and institutional affiliations.

Copyright: () 2020 by the authors. Licensee MDPI, Basel, Switzerland. This article is an open access article distributed under the terms and conditions of the Creative Commons Attribution (CC BY) license (https: / / creativecommons.org/ licenses/by/4.0/).
Department of Materials Science and Engineering, National Dong Hwa University, 1, Sec. 2, Da Hsueh Rd., Shou-Feng, Hualien 974, Taiwan; blackblue1982@gmail.com

* Correspondence: yslindh@gms.ndhu.edu.tw; Tel.: +886-3-8903218

\begin{abstract}
This study proposes AlGaN/GaN/silicon high-electron mobility transistors (HEMTs) grown by a metallorganic chemical vapor deposition (MOCVD) system. The large-signal linearity and high-frequency noise of HEMTs without and with different passivation layers are compared. The experimental data show that the addition of $\mathrm{TiO}_{2}$ passivation layer to undoped $\mathrm{AlGaN} / \mathrm{GaN}$ HEMT's increases the value of the third-order intercept point (OIP3) by up to $70 \%$ at $2.4 \mathrm{GHz}$. Furthermore, the minimum noise figure $\left(N F_{\text {min }}\right)$ of the HEMT with $\mathrm{TiO}_{2}$ passivation is significantly reduced.
\end{abstract}

Keywords: metallorganic chemical vapor deposition (MOCVD); passivation; $\mathrm{HfO}_{2} ; \mathrm{TiO}_{2} ; \mathrm{GaN}$; high-electron mobility transistor (HEMT)

\section{Introduction}

Heterostructure field-effect transistor (HFET) technology has become essential in microwave communication systems [1,2]. III-nitride high-electron-mobility transistors (HEMTs) are of significant importance in the development of next-generation power applications [3-5]. The AlGaN/GaN heterostructure has the advantage of large electron velocity and high breakdown electric field. Furthermore, the polar properties of the AlGaN/GaN heterojunction allows the formation of two-dimensional electron gas (2DEG). Even without intentional doping, the 2DEG concentrations of the AlGaN/GaN HEMTs is as high as the order of $10^{13} \mathrm{~cm}^{-2}$.

Many passivation materials have been investigated to effectively passivate the surface of AlGaAs/InGaAs [6] and InAlAs/InGaAs/InP [7] HEMTs by using either a wet or dry process. The performance of AlGaN/GaN HEMT technology is limited by charge trapping effects. Consequently, various candidates for passivation has been attempted to neutralize the net surface charge arising from the combination of surface states and the polarized barrier [8-18]. Most works focus on the performance of the passivated AlGaN/GaN HEMTs at room temperature. The room-temperature characteristics of AlGaN/GaN HEMT with $\mathrm{HfO}_{2}$ and $\mathrm{TiO}_{2}$ passivation were reported [11]. However, AlGaN/GaN heterostructure is a promising material system for high-temperature electronics. HEMTs that can operate at high temperatures are helpful in broad extent of applications [13,19]. Consequently, the high-temperature characteristics of the passivated AlGaN/GaN HEMTs are measured herein. Furthermore, the linearity in power amplifier is important when we move towards the fifth generation $(5 \mathrm{G})$ wireless systems. Increasing the linearity of HEMTs can supply many advantages at the system level. Consequently, the large-signal linearity of the passivated AlGaN/GaN HEMTs are also studied. To the best of the authors' knowledge, there has not been a comparison of the large-signal linearity and noise figure for the AlGaN/GaN HEMTs with $\mathrm{HfO}_{2}$ and $\mathrm{TiO}_{2}$ passivation. Experimental results demonstrate the high-performance passivated HEMT with stable operation at elevated temperatures up to $420 \mathrm{~K}$. The measured large-signal linearity and high-frequency noise of the passivated HEMT are better than for the identical geometry unpassivated HEMT. 


\section{Device Structure and Experiments}

The studied devices were built on silicon substrate with epilayers that were grown by metal-organic chemical vapor deposition (MOCVD). The layer structure of the HEMT is as follows. First, a buffer was grown, followed by an undoped $\mathrm{GaN}$. Then, $30 \mathrm{~nm}$ undoped $\mathrm{Al}_{0.26} \mathrm{Ga}_{0.74} \mathrm{~N}$ layer was formed and capped by a $2 \mathrm{~nm} \mathrm{GaN}$ layer.

Mesa etching was employed to achieve device isolation. $\mathrm{Ti} / \mathrm{Al} / \mathrm{Au}$ ohmic contacts for the source and drain electrodes were deposited. The gate metallization involved $\mathrm{Ni}$, capped with Au. The HEMT without passivation is the reference HEMT. In our study, the HEMT with $\mathrm{HfO}_{2}$ passivation is referred to as $\mathrm{HfO}_{2}$-HEMT. The HEMTs with $\mathrm{TiO}_{2}$ passivation is referred to as $\mathrm{TiO}_{2}-\mathrm{HEMT}$. The $\mathrm{TiO}_{2}$ film was sputtered in a sputtering system using a three-inch high-purity target of titanium dioxide in a mixture of argon and oxygen gas. $\mathrm{HfO}_{2}$ film was sputtered using hafnium dioxide. Figure 1 displays the layer structure of the studied HEMTs with passivation. The cross section of the passivated HEMTs was investigated by a transmission electron microscopy (TEM) (JEOL Co., Tokto, Japan). The probe station was fitted with a heated device stage. The DC characteristics of the HEMTs were measured with a Keithley 4200 semiconductor characterization system (Tektronix, Beaverton, OR, USA). The field-effect transistor had a gate length of $1 \mu \mathrm{m}$. The gate-to-drain spacing was $2 \mu \mathrm{m}$. The gate-to-source spacing was also $2 \mu \mathrm{m}$.

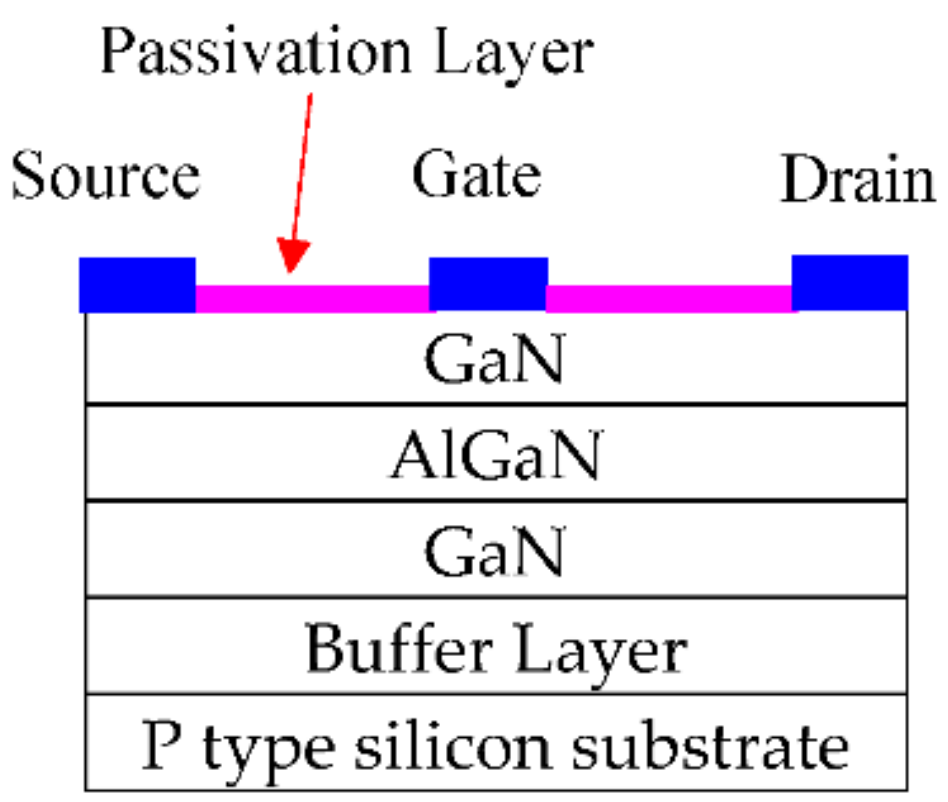

Figure 1. Cross section of the studied passivated AlGaN/GaN high-electron mobility transistor (HEMT).

\section{Results and Discussion}

TEM samples are examined in a JEM-2100F (JEOL Co., Japan) operating at an accelerating voltage of $200 \mathrm{kV}$. Figure 2 illustrates the TEM cross section of the HEMTs with $\mathrm{HfO}_{2}$ and $\mathrm{TiO}_{2}$. The thicknesses of $\mathrm{HfO}_{2}$ and $\mathrm{TiO}_{2}$ films are approximately 22.65 and $19.79 \mathrm{~nm}$, respectively.

The unpassivated and passivated HEMTs are subjected to high-temperature testing. Figure 3 presents the drain currents $\left(I_{\mathrm{DS}}\right)$ at different temperatures versus drain-to-source voltage $\left(V_{\mathrm{DS}}\right)$. The DC measurements are taken as functions of temperatures over the range 300 to $420 \mathrm{~K}$. Figure 4 shows the extrinsic transconductance $\left(g_{\mathrm{m}}\right)$ and drain current versus gate-to-source voltage of the studied HEMTs at various temperatures. The gate voltage swing (GVS) is defined by the voltage range within which the $g_{\mathrm{m}}$ value deviates from its maximum value by $20 \%$. The GVS value is increased from $1.7 \mathrm{~V}$ to $3.2 \mathrm{~V}$ at $300 \mathrm{~K}$ after $\mathrm{TiO}_{2}$ passivation. $I_{\mathrm{DS}}$ versus $V_{\mathrm{DS}}$ at pinch-off conditions and the threshold drain current characteristics at $300 \mathrm{~K}$ for the three HEMTs herein were studied [11]. Figure 5a plots 
drain current at $V_{\mathrm{GS}}=0 \mathrm{~V}$ (I $\left.I_{\mathrm{DSS}}\right)$ versus temperature of the studied HEMTs. Experimental results reveal that $I_{\text {DSS }}$ values of the studied HEMTs are increased when the HEMTs are passivated. The increased drain current density is attributable to the increased sheet electron concentration after passivation $[8,11]$. The studied three HEMTs depicts good pinch-off characteristics at various temperatures. Increasing the temperature decreases $I_{\mathrm{DSS}}$. The falloff in drain current density at elevated temperatures result from the degradation of the electron mobility. Furthermore, the threshold voltage $\left(V_{\text {th }}\right)$ is extracted by linear extrapolation of the root of drain current against $V_{\mathrm{g}}$ curves. The values of $V_{\text {th }}$ of the $\mathrm{TiO}_{2}$-HEMT are $-5.5,-5.33,-5.2,-4.96$, and $-4.89 \mathrm{~V}$ at $300,330,360,390$, and $420 \mathrm{~K}$, respectively. The magnitude of the $V_{\text {th }}$ value is reduced at high temperature because of the decreased drain current density.

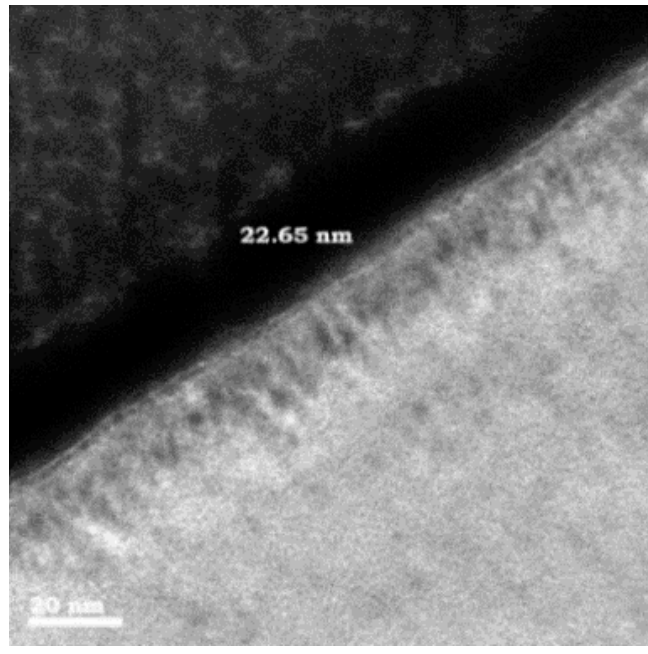

(a)

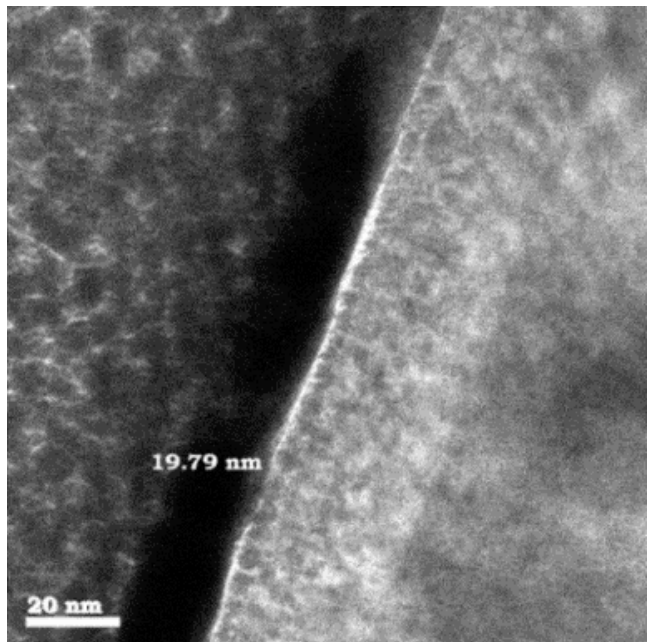

(b)

Figure 2. Cross-sectional TEM images of (a) $\mathrm{HfO}_{2}$-HEMT and (b) $\mathrm{TiO}_{2}$-HEMT.
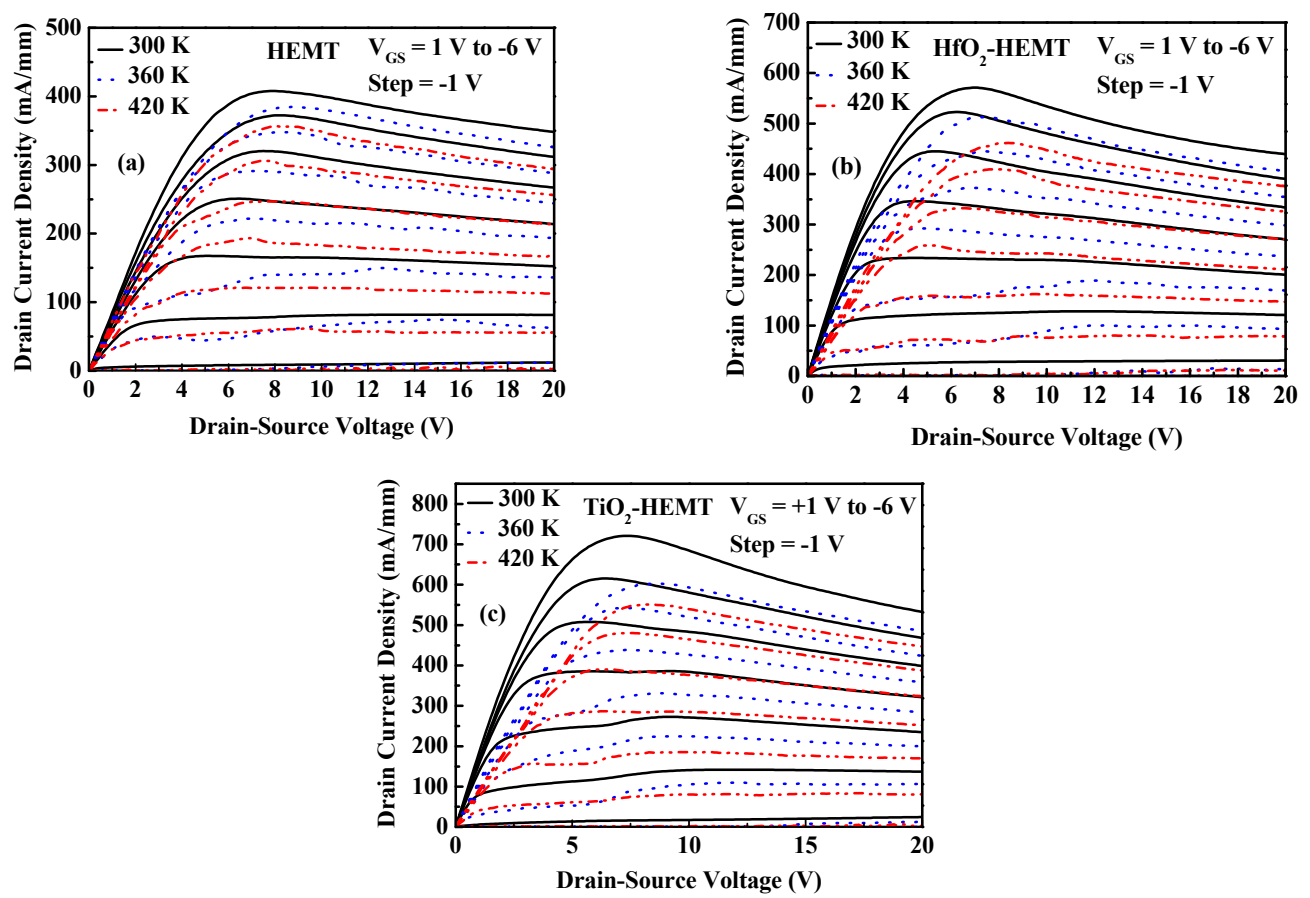

Figure 3. Family of drain-source output curves of (a) $\mathrm{HEMT}$, (b) $\mathrm{HfO}_{2}-\mathrm{HEMT}$, and (c) $\mathrm{TiO}_{2}-\mathrm{HEMT}$ at various temperatures. 


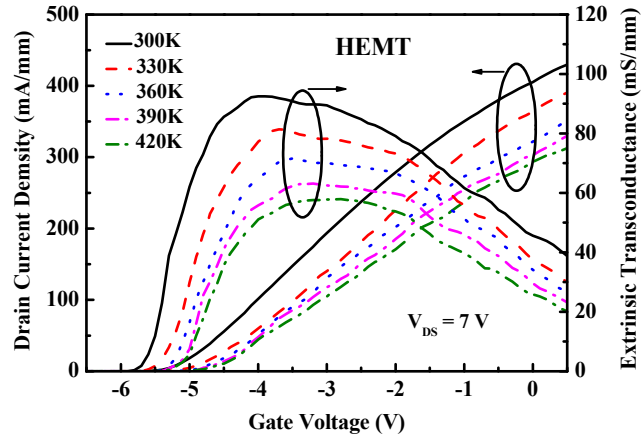

(a)

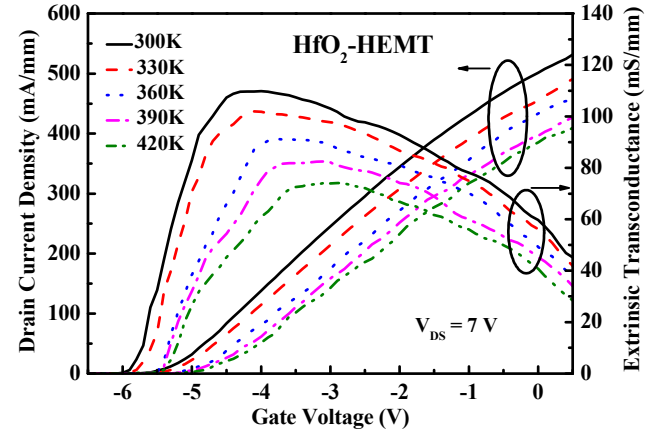

(b)

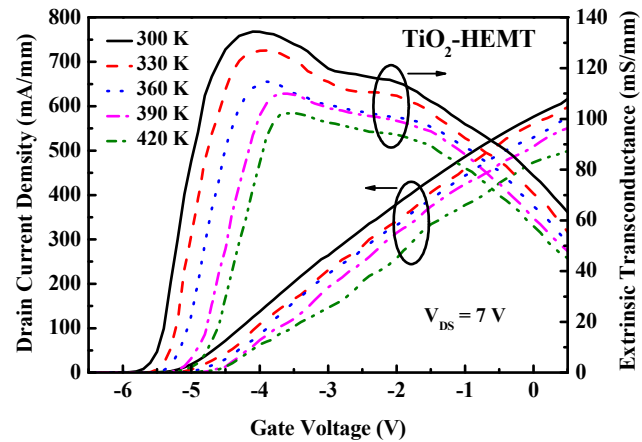

(c)

Figure 4. Extrinsic transconductance and drain current characteristics of (a) $\mathrm{HEMT}$, (b) $\mathrm{HfO}_{2}-\mathrm{HEMT}$, and (c) TiO $2-\mathrm{HEMT}$ at various temperatures.
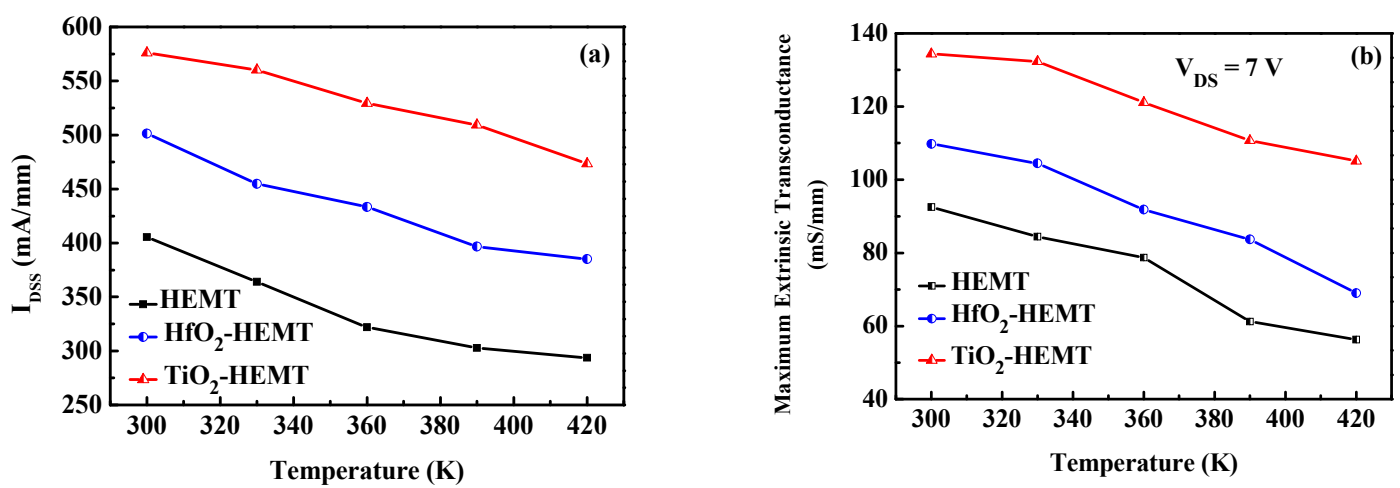

Figure 5. (a) $I_{\mathrm{DSS}}$ and (b) $g_{\mathrm{m}, \max }$ of the studied HEMTs at various temperatures.

Figure $5 \mathrm{~b}$ plots the maximum extrinsic transconductance $\left(g_{\mathrm{m}, \max }\right)$ versus temperature of the investigated HEMTs. When the temperature is increased, the maximum extrinsic transconductance varies in the same tendency as $I_{\text {DSs. }}$. At $420 \mathrm{~K}$, the $g_{\mathrm{m}}$, max values for HEMT, $\mathrm{HfO}_{2}-\mathrm{HEMT}$, and $\mathrm{TiO}_{2}-\mathrm{HEMT}$ are 56.3, 69, and $105 \mathrm{mS} / \mathrm{mm}$, respectively. Experimental results demonstrate the $\mathrm{TiO}_{2}-\mathrm{HEMT}$ perform well even at high temperatures.

Two-tone intermodulation distortion is measured to demonstrate the large-signal linearity performance. Figure 6 shows the fundamental and third-order output powers versus input power of the studied devices. The red dashed lines are extrapolated to predict the intersection at the third-order intercept point (OIP3). The values of OIP3 are 10.5, 13.7, and $17.9 \mathrm{dBm}$, respectively. $\mathrm{HfO}_{2}$ passivation increases the OIP3 value by around $30 \%$ and $\mathrm{TiO}_{2}$ passivation increases it by $70 \%$. The large-signal linearity of the HEMT is significantly improved when the HEMT is passivated by $\mathrm{TiO}_{2}$. The improved device linearity of the $\mathrm{TiO}_{2}$-HEMT is attributed to increased $g_{\mathrm{m}, \max }[18]$ and GVS values [20]. 

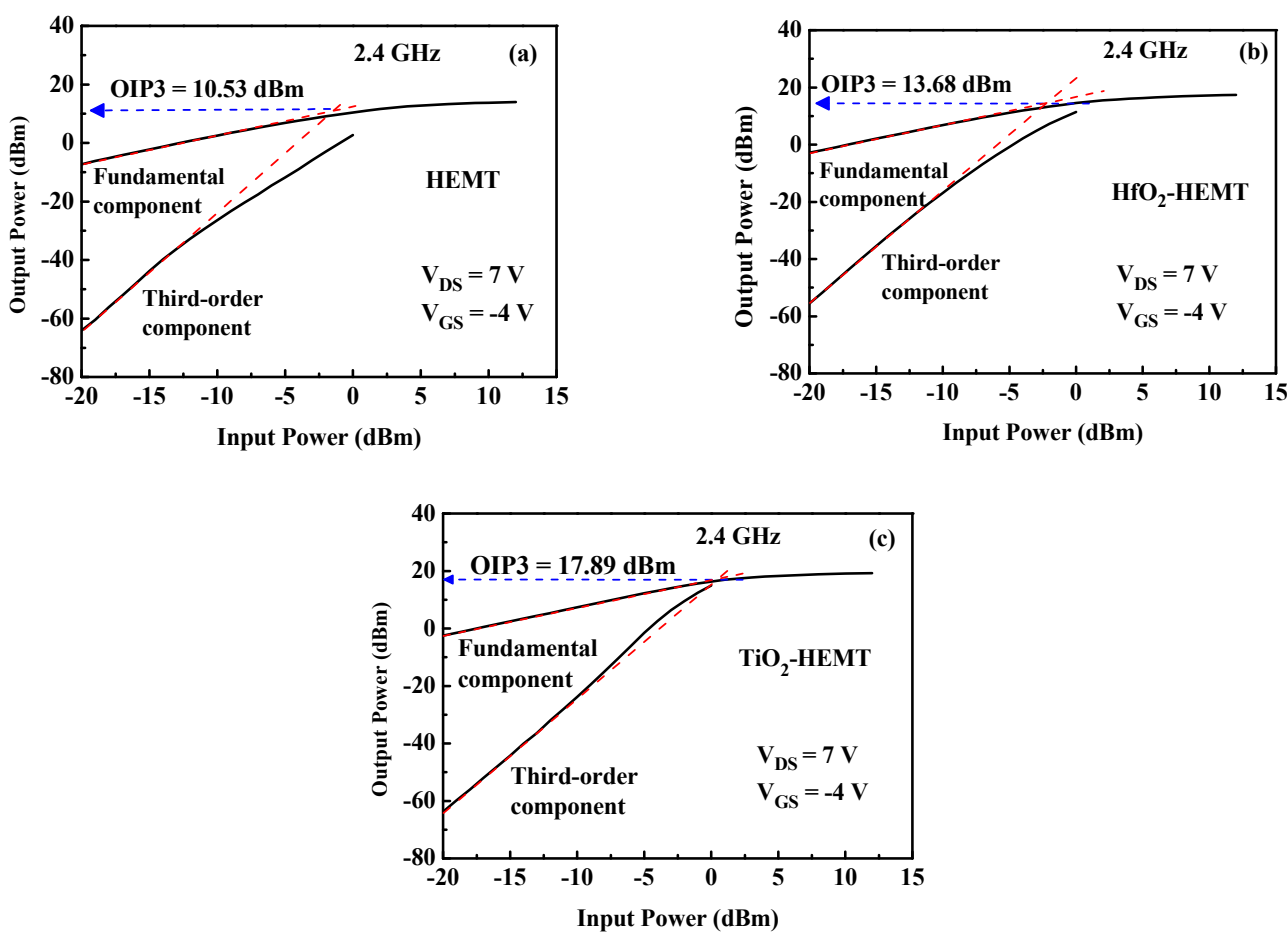

Figure 6. Fundamental output power and third-order intermodulation component of (a) HEMT, (b) $\mathrm{HfO}_{2}-\mathrm{HEMT}_{\text {, }}$ and (c) $\mathrm{TiO}_{2}$-HEMT.

Noise figure is measured over the 2-6 GHz frequency range using an ATN NP5B noise parameter test set in conjunction with the HP-8510C network analyzer. Figure 7 shows the minimum noise figure $\left(N F_{\min }\right)$ and associated power gain $\left(G_{\mathrm{a}}\right)$ versus frequency for the studied HEMTs. Figure 7 reveals that the relationship between the noise and frequency is near linear. Quantitatively, $N F_{\min }$ is given by [21-23]

$$
N F_{\min }=1+2 \pi f k C_{g s} \sqrt{\frac{R_{s}+R_{g}}{g_{m}}}
$$

where $f$ is frequency; $k$ is the Fukui constant; $C_{g s}$ is the input gate-source capacitance; $R_{\mathrm{s}}$ is the source series resistance, and $R_{\mathrm{g}}$ is the gate series resistance. The $N F_{\min }$ values of HEMT, $\mathrm{HfO}_{2}$-HEMT, and $\mathrm{TiO}_{2}$-HEMT are $1.94 \mathrm{~dB}, 1.79 \mathrm{~dB}$, and $1.68 \mathrm{~dB}$. The $\mathrm{TiO}_{2}-\mathrm{HEMT}$ has the smallest $N F_{\min }$ of the three devices because it has the highest $g_{\mathrm{m}}$. Furthermore, the associate gain of the $\mathrm{TiO}_{2}$-HEMT is also improved.

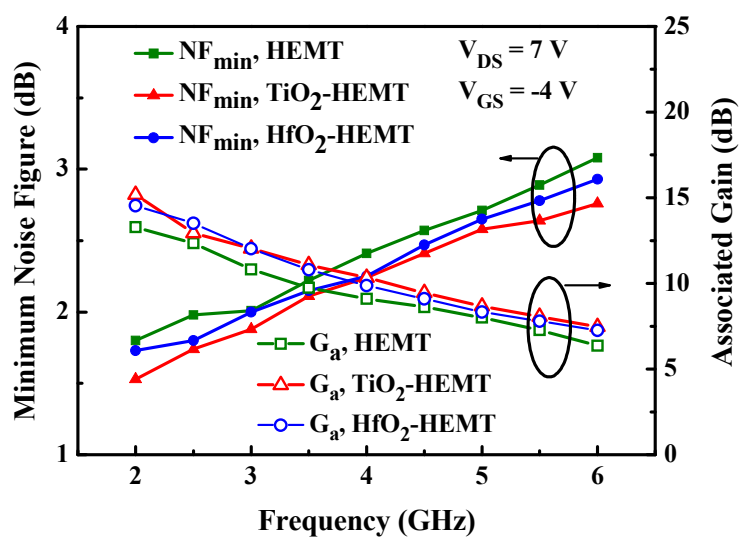

Figure 7. Minimum noise figure and associated gain of the studied (a) HEMT, (b) $\mathrm{HfO}_{2}-\mathrm{HEMT}$, and $\mathrm{TiO}_{2}-\mathrm{HEMT}$. 


\section{Conclusions}

$\mathrm{AlGaN} / \mathrm{GaN} /$ silicon grown by MOCVD have been successfully fabricated and measured. The high-temperature characteristics of the proposed devices are investigated. $\mathrm{TiO}_{2}$-HEMT exhibits the best large-signal linearity of the studied devices. Furthermore, the $\mathrm{NF}_{\min }$ value of $\mathrm{TiO}_{2}$-HEMT is smallest of the studied devices herein.

Author Contributions: Investigation, Y.-S.L.; data curation, S.-F.L.; writing, Y.-S.L.; supervision, Y.-S.L. All authors have read and agreed to the published version of the manuscript.

Funding: This research was funded by the Ministry of Science and Technology, Taiwan, grant number MOST 108-2221-E-259-002-MY2.

Conflicts of Interest: The authors declare no conflict of interest.

\section{References}

1. Wang, T.B.; Hsu, W.C.; Su, J.L.; Hsu, R.T.; Wu, Y.H.; Lin, Y.S.; Su, K.H. Comparison of $\mathrm{Al}_{0.32} \mathrm{Ga}_{0.68} \mathrm{~N} / \mathrm{GaN}$ Heterostructure Field-Effect Transistors with Different Channel Thicknesses. J. Electrochem. Soc. 2007, 154, H131-H133. [CrossRef]

2. Hung, C.W.; Chang, C.H.; Chen, W.C.; Chen, C.C.; Chen, H.I.; Tsai, Y.T.; Tsai, J.H.; Liu, W.C. A Pt/AlGaN/GaN Heterostructure Field-Effect Transistor (HFET) Prepared by an Electrophoretic Deposition (EPD)-Gate Approach. Solid-State Electron. 2016, 124, 5-9. [CrossRef]

3. Wojtasiak, W.; Góralczyk, M.; Gryglewski, D.; Zając, M.; Kucharski, R.; Prystawko, P.; Piotrowska, A.; Ekielski, M.; Kamińska, E.; Taube, A.; et al. AlGaN/GaN High Electron Mobility Transistors on Semi-Insulating Ammono-GaN Substrates with Regrown Ohmic Contacts. Micromachines 2018, 9, 546. [CrossRef] [PubMed]

4. Abid, I.; Kabouche, R.; Bougerol, C.; Pernot, J.; Masante, C.; Comyn, R.; Cordier, Y.; Medjdoub, F. High Lateral Breakdown Voltage in Thin Channel, AlGaN/GaN High Electron Mobility Transistors on AlN/Sapphire Templates. Micromachines 2019, 10, 690. [CrossRef]

5. $\quad$ Lin, Y.C.; Chen, S.H.; Lee, P.H.; Lai, K.H.; Huang, T.J.; Chang, E.Y.; Hsu, H.T. Gallium Nitride (GaN) High-Electron-Mobility Transistors with Thick Copper Metallization Featuring a Power Density of $8.2 \mathrm{~W} / \mathrm{mm}$ for Ka-Band Applications. Micromachines 2020, 11, 222. [CrossRef]

6. Lin, Y.S.; Chen, B.Y. Effects of Surface Passivation and Temperature on AlGaAs/InGaAs High-Electron Mobility Transistor. Microelectron. Eng. 2019, 214, 100-103. [CrossRef]

7. Han, D.; Ruiz, D.C.; Bonomo, G.; Saranovac, T.; Ostinelli, O.J.S.; Bolognesi, C.R. Low-Noise Microwave Performance of 30 nm GaInAs MOS-HEMTs: Comparison to Low-Noise HEMTs. IEEE Electron Device Lett. 2020, 41, 1320-1323. [CrossRef]

8. Liu, C.; Chor, E.F.; Tan, L.S. Enhanced device performance of AlGaN/GaN HEMTs Using $\mathrm{HfO}_{2} \mathrm{High}_{-\mathrm{k}}$ Dielectric for Surface Passivation and Gate Oxide. Semicond. Sci. Tech. 2007, 22, 522-527. [CrossRef]

9. Fitch, R.C.; Walker, D.E., Jr.; Chabak, K.D.; Gillespie, J.K.; Kossler, M.; Trejo, M.; Crespo, A.; Liu, L.; Kang, T.S.; Lo, C.-F.; et al. Comparison of Passivation Layers for AlGaN/GaN High Electron Mobility Transistors. J. Vac. Sci. Technol. B 2011, 29, 061204. [CrossRef]

10. Fehlberg, T.B.; Milne, J.S.; Umana-Membreno, G.A.; Keller, S.; Mishra, U.K.; Nener, B.D.; Parish, G. Transport Studies of $\mathrm{AlGaN} / \mathrm{GaN}$ Heterostructures of Different Al Mole Fractions with Variable $\mathrm{SiN}_{\mathrm{x}}$ Passivation Stress. IEEE Trans. Electron Devices 2011, 58, 2589. [CrossRef]

11. Lin, Y.S.; Lin, S.F.; Hsu, W.C. Microwave and power characteristics of AlGaN/GaN/Si High-Electron Mobility Transistors with $\mathrm{HfO}_{2}$ and $\mathrm{TiO}_{2}$ Passivation. Semicond. Sci. Technol. 2015, 30, 015016. [CrossRef]

12. Geng, K.; Chen, D.; Zhou, Q.; Wang, H. AlGaN/GaN MIS-HEMT with PECVD SiN ${ }_{\mathrm{x}}, \mathrm{SiON}, \mathrm{SiO}_{2}$ as Gate Dielectric and Passivation Layer. Electronics 2018, 7, 416. [CrossRef]

13. Lin, Y.S.; Goa, W.H. High-temperature Stability of Improved AlGaN/AlN/GaN HEMT with Pre-Gate Metal Treatment. IEICE Electron. Express 2019, 16, 1-8. [CrossRef]

14. Gao, S.; Zhou, Q.; Liu, X.; Wang, H. Breakdown Enhancement and Current Collapse Suppression in AlGaN/GaN HEMT by $\mathrm{NiOx} / \mathrm{SiNx}$ and $\mathrm{Al}_{2} \mathrm{O}_{3} / \mathrm{SiN}_{\mathrm{x}}$ as Gate Dielectric Layer and Passivation layer. IEEE Electron Device Lett. 2019, 40, 1921-1924. [CrossRef]

15. Cheng, K.Y.; Wu, S.C.; Yu, C.J.; Wang, T.W.; Liao, J.H.; Wu, M.C. Comparative Study on Performance of AlGaN/GaN MS-HEMTs with $\mathrm{SiN}_{\mathrm{x}}, \mathrm{SiO}_{\mathrm{x}}$, and SiNO Surface Passivation. Solid-State Electron. 2020, 170, 107824. [CrossRef]

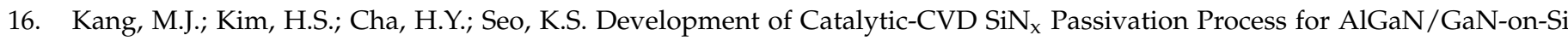
HEMTs. Crystals 2020, 10, 842. [CrossRef]

17. Murugapandiyan, P.; Mohanbabu, A.; Lakshmi, V.R.; Ramakrishnan, V.N.; Varghese, A.; Wasim, M.O.H.D.; Baskaran, S.; Kumar, R.S.; Janakiraman, V. Performance Analysis of $\mathrm{HfO}_{2}$ /InAlN/AlN/GaN HEMT with AlN Buffer Layer for High Power Microwave Applications. J. Sci. 2020, 5, 192-198. [CrossRef] 
18. Shrestha, P.; Guidry, M.; Romanczyk, B.; Hatui, N.; Wurm, C.; Krishna, A.; Pasayat, S.S.; Karnaty, R.R.; Keller, S.; Buckwalter, J.F.; et al. High Linearity and High Gain Performance of N-Polar GaN MIS-HEMT at $30 \mathrm{GHz}$. IEEE Electron Device Lett. 2020, 41, 681-684. [CrossRef]

19. Li, S.; Liu, S.; Tian, Y.; Zhang, C.; Wei, J.; Tao, X.; Li, N.; Zhang, L.; Sun, W. High-Temperature Electrical Performances and Physics-Based Analysis of p-GaN HEMT Device. IET Power Electron. 2020, 13, 420-425. [CrossRef]

20. Mi, M.; Wu, S.; Zhang, M.; Yang, L.; Hou, B.; Zhao, Z.; Guo, L.; Zhang, X.; Ma, X.; Hao, Y. Improving the Transconductance Flatness of InAlN/GaN HEMT by Modulating $\mathrm{V}_{\mathrm{T}}$ along the Gate Width. Appl. Phys. Express 2019, 12, 114001. [CrossRef]

21. Fukui, H. Optimal Noise Figure of Microwave GaAs MESFET's. IEEE Trans. Electron Devices 1979, 26, 1032-1037. [CrossRef]

22. Fukui, H. Design of microwave GaAs MESFET'S for Broad-Band Low-Noise Amplifiers. IEEE Trans. Microw. Theory Tech. 1979, 27, 643-650. [CrossRef]

23. Delagebeaudeuf, D.; Chevrier, J.; Laviron, M.; Delescluse, P. A New Relationship between the Fukui Coefficient and Optimal Current Value for Low-Noise Operation of Field-Effect Transistors. IEEE Electron Device Lett. 1985, 6, 444-445. [CrossRef] 